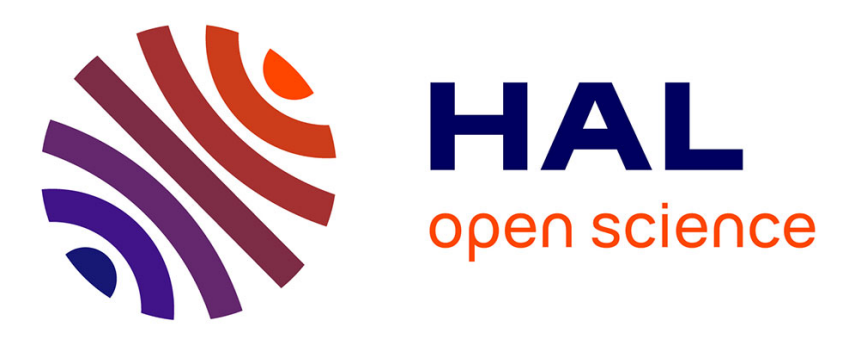

\title{
S -(Diethyl \\ phosphonodifluoromethyl)Benzenesulfonothioate: A \\ New Reagent for the Synthesis of SCF 2 PO(OEt) 2 -containing Molecules
}

Fabien Petit-Cancelier, Benjamin François, Xavier Pannecoucke, Samuel Couve-Bonnaire, Tatiana Besset

\section{To cite this version:}

Fabien Petit-Cancelier, Benjamin François, Xavier Pannecoucke, Samuel Couve-Bonnaire, Tatiana Besset. S -(Diethyl phosphonodifluoromethyl)Benzenesulfonothioate: A New Reagent for the Synthesis of SCF 2 PO(OEt) 2 -containing Molecules. Advanced Synthesis and Catalysis, 2019, 362 (4), pp.760-764. 10.1002/adsc.201901454 . hal-02455768

HAL Id: hal-02455768

https://hal-normandie-univ.archives-ouvertes.fr/hal-02455768

Submitted on 8 Dec 2020

HAL is a multi-disciplinary open access archive for the deposit and dissemination of scientific research documents, whether they are published or not. The documents may come from teaching and research institutions in France or abroad, or from public or private research centers.
L'archive ouverte pluridisciplinaire HAL, est destinée au dépôt et à la diffusion de documents scientifiques de niveau recherche, publiés ou non, émanant des établissements d'enseignement et de recherche français ou étrangers, des laboratoires publics ou privés. 


\section{S-(Diethyl Phosphonodifluoromethyl)Benzenesulfono- thioate: A New Reagent for the Synthesis of $\mathrm{SCF}_{2} \mathrm{PO}(\mathrm{OEt})_{2}-$ containing Molecules.}

Fabien Petit-Cancelier, ${ }^{a}$ Benjamin François, ${ }^{a}$ Xavier Pannecoucke, ${ }^{a}$ Samuel Couve-Bonnaire ${ }^{a}$ and Tatiana Besset ${ }^{\text {a* }}$

aNormandie Univ, INSA Rouen, UNIROUEN, CNRS, COBRA (UMR 6014), 76000 Rouen, France.

E-mail: tatiana.besset@insa-rouen.fr

Abstract: In this manuscript, the synthesis of an original $\mathrm{SCF}_{2} \mathrm{PO}(\mathrm{OEt})_{2}$-containing reagent was depicted. Thanks to the unique properties of this newly-designed source, an unprecedented transformation with aldehydes was conducted under radical conditions, offering an access to high value-added fluoroalkylthio compounds. Preliminary mechanistic studies were conducted and supported a radical reaction mechanism. Remarkably, thiol and disulfide derivatives turned out to be suitable coupling partners in a transition metal free transformation towards the synthesis of difficult-to-synthesize unsymmetrical disulfides. Finally, the difunctionalization of the 4-phenyl-butene was investigated with this reagent.

The synthesis of organofluorine molecules is still nowadays a compelling challenge due to the importance of the fluorinated compounds ${ }^{[1]}$ in pharmaceutical and agrochemical industries. ${ }^{[2]}$ Thanks to the properties of the fluorine atom and the fluorinated groups ${ }^{[3]}$ features of the fluorine-containing molecules might be tuned at will. In particular, to further meet the demand of original fluorinated groups for academia and industrial applications, several research groups investigated the design and the incorporation of $\mathrm{SCF}_{2} \mathrm{R}$ moieties (R = H, F, FG, FG = functional group) onto molecules. ${ }^{[4]}$ In particular, a strong interest was shown towards the $\mathrm{SCF}_{2} \mathrm{PO}(\mathrm{OEt})_{2}$ residue (Hansch-Leo parameter of $\left.\pi=0.76\right) .{ }^{[5]}$ Key reports generally dealt with the construction of this fluorinated group $^{[6]}$ or its direct introduction using an electrophilic reagent on various classes of compounds. ${ }^{[5,7]}$ Nevertheless, despite these major advances, some synthetic limitations remain. To overcome them and since no radical $\mathrm{SCF}_{2} \mathrm{PO}(\mathrm{OEt})_{2}$-source existed, we thought that the design of a new reagent would be relevant, offering new chemical spaces for the functionalization of other classes of molecules with this fluorinated building block. Taking benefit from our in-home expertise ${ }^{[5,7]}$ we envisioned at first to use $\mathrm{ArSSCF}_{2} \mathrm{PO}(\mathrm{OEt})_{2}$ derivatives as the $\mathrm{SCF}_{2} \mathrm{PO}(\mathrm{OEt})_{2}$ radical source. Unfortunately, all attempts with different classes of compounds only led to the preferential incorporation of the ArS moiety instead of the desired fluorinated group. We reasoned that to reach the targeted goal, one solution relied on the "dessymetrization" of the S-S bond from the reagent in order to favor the incorporation of the $\mathrm{SCF}_{2} \mathrm{PO}(\mathrm{OEt})_{2}$ moiety. In the course of our investigations and inspired by the key advances made by several research groups, ${ }^{[4 b]}$ we anticipated that the reactivity of a $\mathrm{ArSO}_{2} \mathrm{SCF}_{2} \mathrm{PO}(\mathrm{OEt})_{2}$ reagent would be tailor-made as it should favor the targeted transfer of the $\mathrm{SCF}_{2} \mathrm{PO}(\mathrm{OEt})_{2}$ over the $\mathrm{ArSO}_{2}$ group. In this context, the design and the synthesis of the reagent II was achieved by mixing our in-home reagent $\mathbf{I}$ and sodium para-toluenesulfinate in acetic acid for $16 \mathrm{~h}$ at room temperature. Pleasingly, under these reaction conditions, the reagent II was obtained in $81 \%$ yield and its synthesis was easily scaled up to about $1 \mathrm{~g}$ with a similar yield $(3.25 \mathrm{mmol}, 89 \%)$. Note that under acidic conditions, the reagent II is quite stable while its decomposition was observed in the presence of various bases in dichloromethane as a solvent. ${ }^{[8]}$

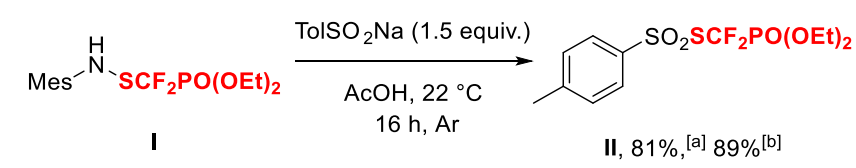

Scheme 1. Synthesis of the new $\mathrm{SCF}_{2} \mathrm{PO}(\mathrm{OEt})_{2}$ reagent II. ${ }^{[a]}$ Reaction performed on $1.13 \mathrm{mmol}$ scale. ${ }^{[b]}$ Reaction performed on $3.25 \mathrm{mmol}$ scale. Mes = mesityl

The reactivity of the reagent II was evaluated for the synthesis of diethyl phosphonodifluoromethylated thioesters (Scheme 2). Indeed, the direct introduction of the $\mathrm{SCF}_{2} \mathrm{PO}(\mathrm{OEt})_{2}$ moiety was smoothly achieved when combining $\mathrm{NaN}_{3}$ and PIFA in a green solvent (EtOAc) at room temperature. A series of aromatic aldehydes $(\mathbf{1 a}-\mathbf{1} \mathbf{u})$ were engaged in our standard conditions. It turned out that electron rich substrates $(\mathbf{1 b} \mathbf{b} \mathbf{1 g})$ were efficiently functionalized and the reaction was scaled up to $1 \mathrm{mmol}$ scale in case of 1b leading to the corresponding product in a slightly lower yield (65\% vs $79 \%)$. The transformation was tolerant to various functional groups such as alcohol (2c), halogens (2i-2k and $\mathbf{2 0}$ ) and nitrile (2q). In case of electron poor aromatic aldehydes (compounds $\mathbf{1 h}, \mathbf{1 l}, \mathbf{1 p}-\mathbf{1 q}$ ), a slight modification of the reaction conditions was necessary to ensure the synthesis of the corresponding diethyl 
phosphonodifluoromethylated thioesters in satisfactory yields (up to $61 \%$ yield). The substitution pattern on the aromatic ring did not have a strong impact on the outcome of the reaction as meta and ortho substituted aromatic aldehydes with electron rich and poor substituents $(\mathbf{1 m}-\mathbf{1 s})$ were converted into the expected products $(\mathbf{2 m - 2 s})$ in moderate to high yields. This allowed us to functionalize compounds of interest such as the Bn-protected vanillin (1) and syringaldehyde (1u), offering an access to the corresponding diethyl phosphonodifluoromethylated thioesters in $66 \%$ and $68 \%$ yields, respectively. Heteroaromatic aldehydes such as pyrrole-2-carboxaldehyde 1v, 2-thiophenecarboxaldehyde $\mathbf{1 w}$ and benzo[b]thiophene-2-carboxaldehyde $\mathbf{1 x}$ were also smoothly converted into the corresponding fluorinated products $\mathbf{2 v - 2 x}$ in low to moderate yields. When an aliphatic aldehyde was engaged, $2 \mathbf{y}$ was obtained in $40 \%$ yield due to purification issues. Finally, due to the importance of fluoroalkylthio moieties in bioactive molecules, ${ }^{[2 a]}$ the synthetic value of the methodology was further proven by the late-stage functionalization of a complex molecule namely the cholesterol derivative $1 \mathbf{z}$.
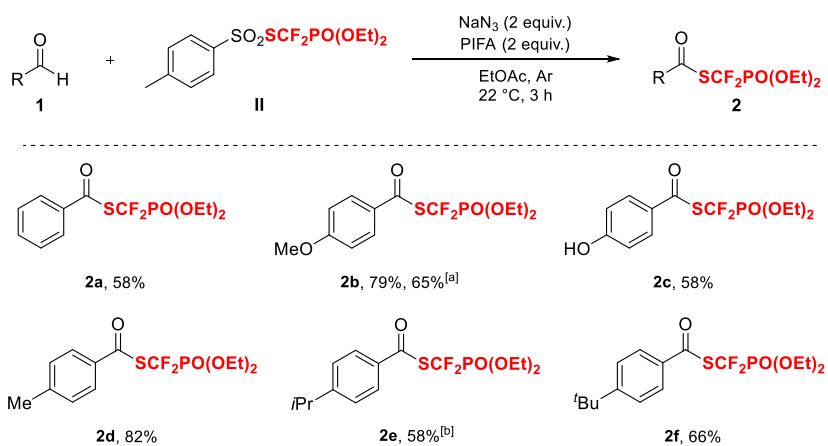

$2 d, 82 \%$

$2 \mathrm{e}, 58 \%^{[\mathrm{b}]}$<smiles>CCOCCOC(=O)c1ccc(Cl)cc1</smiles><smiles>CCOCCOCCOCCOCC</smiles><smiles>CCOCCOCCOCCOCCOCC</smiles>

2g, $60 \%$

$2 h, 74 \%[c],[d]$

2i, $50 \%$<smiles>CCOCCOCC#CC(=O)c1ccc(Br)cc1</smiles><smiles>CCOCCOC(=O)c1ccc(F)cc1</smiles><smiles>CCOCCOCCOC(=O)c1ccc(C(F)(F)F)cc1</smiles>

2j, $41 \%$

2k, $46 \%$

$21,61 \%\left[{ }^{[c]}\right.$<smiles>CCOC=[Ru+]C(=O)c1cccc(OC)c1</smiles><smiles>CCOCCOC(=O)c1cccc([N+](=O)[O-])c1</smiles><smiles>CCOCCOCCOCC</smiles>

$2 m, 48 \%$

2n, $78 \%$

$20,87 \%[0]$<smiles>CCOCCOCCOC(=O)c1cccc(C(F)(F)F)c1</smiles><smiles>CCOC=[Ru+]C(=O)c1cccc(C#N)c1</smiles><smiles>CCOCCOCC#CC(=O)c1ccccc1OC</smiles>

2p. $44 \%[c],[e]$

2q. $51 \%$

$2 \mathrm{r}, 52 \%$

Me

$\mathrm{SCF}_{2} \mathrm{PO}(\mathrm{OEt})_{2}$<smiles>CCOCCOCC#CC(=O)c1ccc(OCC)c(OC)c1</smiles><smiles>CCOCCOCCOCCOc1cc(C(=O)OCC)cc(OC)c1OCc1ccccc1</smiles>

2s, $67 \%$

$2 t, 66 \%$ $2 \mathrm{u}, 68 \%^{[\mathrm{b}]}$<smiles>CCOC=C=C(C#CCOCC)c1ccc[nH]1</smiles>

2v, $56 \%$<smiles>CCCCC(=O)[Pb]OCC</smiles>

$2 \mathbf{y}, 40 \%$<smiles>CCOCCOC(=O)c1cccs1</smiles>

2w, $34 \%$<smiles>CCOCCOCC#[As]C(=O)c1cc2ccccc2s1</smiles>

$2 \mathrm{x}, 30 \%{ }^{[\mathrm{d}]}$

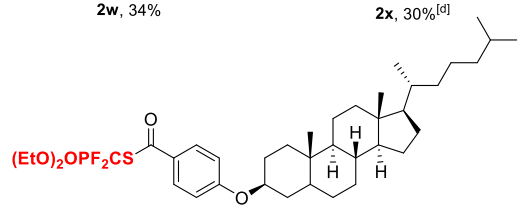

2z, $63 \%$ [d]

Scheme 2. Synthesis of diethyl phosphonodifluoromethylated thioesters from aldehydes using the reagent II. Reaction performed on 0.2 mmol scale: aldehyde 1 ( $0.2 \mathrm{mmol})$, reagent II $(0.3 \mathrm{mmol}), \mathrm{NaN}_{3}$ (2 equiv.), PIFA (2 equiv.) in EtOAc at $22^{\circ} \mathrm{C}$ for $3 \mathrm{~h}$ under argon. Isolated yields were given. ${ }^{[a]}$ Reaction on 1 mmol scale. ${ }^{[b]} 6 \mathrm{~h}$ instead of $3 \mathrm{~h}$. ${ }^{[c]}$ The reaction was carried out using 0.4 mmol of aldehyde 1, 0.2 mmol of reagent II, NaN ${ }_{3}$ (2 equiv.), PIFA (2 equiv.) in $\mathrm{CH}_{2} \mathrm{Cl}_{2}$ at $22^{\circ} \mathrm{C}$ for $16 \mathrm{~h}$ under argon. ${ }^{[\mathrm{d}]}$ The product was isolated in the presence of an inseparable impurity. [e] Reaction carried out at $27^{\circ} \mathrm{C}$ 
Control experiments were conducted to get more insights into the reaction mechanism. The addition of 2,2,6,6tetramethylpiperidine 1-oxyl (TEMPO) or 2,6-di-tert-butyl-4-methylphenol (BHT) as radical inhibitors completely inhibited the reaction, whatever the added quantity. ${ }^{[8]}$ In case of 2 equivalents of TEMPO, the corresponding TEMPO adduct was detected by GC-HRMS. Note that when PIFA and TEMPO were mixed, no degradation of the PIFA was observed. Therefore, based on these observations and literature data, ${ }^{[9]}$ the following tentative mechanism was proposed (Scheme 3): after generation of the radical azide from sodium azide in the presence of PIFA, the corresponding acyl radical was obtained. The latter reacted with the reagent II to afford the expected product 2.

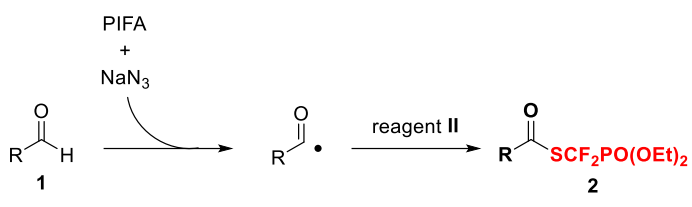

Scheme 3. Plausible mechanism.

The reagent II was not only efficient for the functionalization of aldehyde derivatives, and other classes of compounds were evaluated. Indeed, when thiol $\mathbf{3}$ or disulfide $\mathbf{4}$ derivatives were engaged with the reagent II in the presence of $\mathrm{LiBr},{ }^{[10]}$ the synthesis of difficult-to-synthesize unsymmetrical disulfides was successfully achieved (12 examples, up to $91 \%$ yields, Scheme 4). This transition metal-free approach was efficient offering a panel of para substituted aromatic diethyl phosphonodifluoromethylthiolated compounds bearing electron-donating groups ( $\mathbf{5 b}$ and $\mathbf{5 c}$, in $72 \%$ and $52 \%$ yields, respectively) as well as halogens (5d and $\mathbf{5 e}$ ) and a $\mathrm{CF}_{3}$ moiety (5f), the reaction being more efficient for electron rich systems. The substitution pattern on the aromatic ring did have a strong effect on the outcome of the reaction as demonstrated when comparing $\mathbf{5 c}, \mathbf{5 g}$ and $\mathbf{5 h}$. Note that a thiophene derivative was a reluctant substrate under these reaction conditions providing the expected compounds in only $22 \%$ yield. Pleasingly, the functionalization of aliphatic thiol derivatives was achieved not only with the benzylic derivative $5 \mathbf{j}$ but also with unactivated aliphatic derivatives (5k and $\mathbf{5 I}$ ). This showcased the added-value of this approach compared to the existing methods, ${ }^{[7]}$ and demonstrated further its synthetic utility.

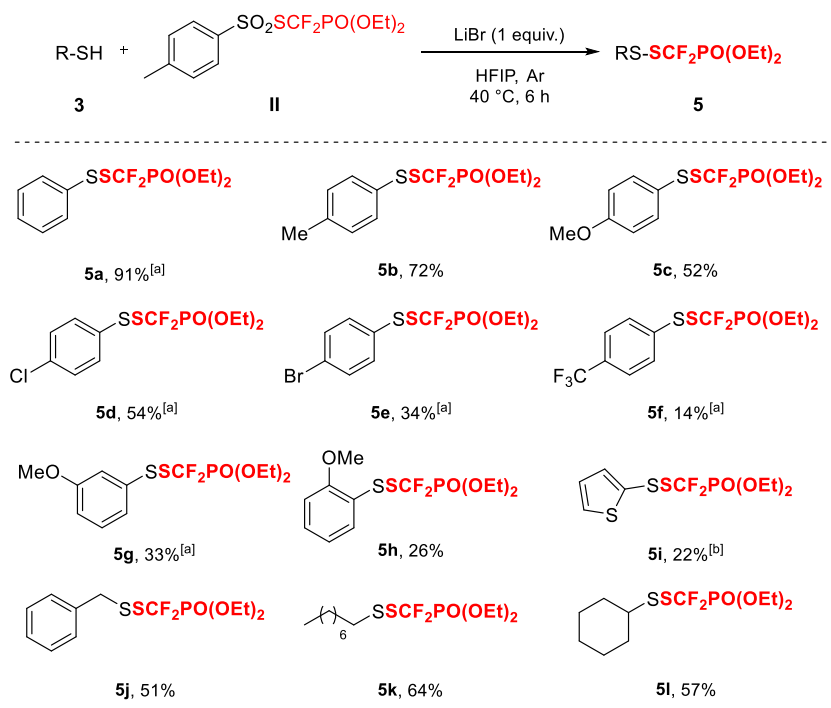

Scheme 4. Synthesis of unsymmetrical fluorinated disulfides 5 . Reaction conditions: RSH $3(0.20 \mathrm{mmol})$, reagent II (0.2 mmol), LiBr (1 equiv.) in $\mathrm{HFIP}$ at $40^{\circ} \mathrm{C}$ for $6 \mathrm{~h}$ under argon. Isolated yields were given. ${ }^{[a]}$ Reaction performed using $(\operatorname{ArS})_{2} 4$ instead of 3 . ${ }^{[b]}$ The product was isolated in the presence of an inseparable impurity.

Aiming at demonstrating further the synthetic potential of the reagent II, the difunctionalization of unactivated alkenes was studied. ${ }^{[11]}$ After intensive investigations, the diethyl phosphonodifluoro-methylthiolation sulfonylation of $\mathbf{6}$ was achieved leading to the corresponding product 7 , although in a low yield (21\%) despite all our efforts (Scheme 5). Nevertheless, the transformation was highly atom-economical and regioselective as 7 was obtained as a single regioisomer. ${ }^{[8]}$ 


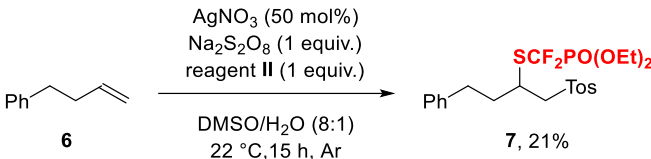

Scheme 5. Difunctionalization of the 4-phenyl-butene.

In summary, the synthesis of an original $\mathrm{SCF}_{2} \mathrm{PO}(\mathrm{OEt})_{2}$ reagent was achieved and its reactivity was investigated. Indeed, the direct diethyl phosphonodifluoromethylthiolation of aldehydes provided an access to unprecedented thioester derivatives. Preliminary mechanistic studies indicated a radical pathway. Moreover, the access to unsymmetrical $\mathrm{SCF}_{2} \mathrm{PO}(\mathrm{OEt})_{2}$-containing (hetero)aromatic, benzylic and non-activated aliphatic disulfides was achieved. With the reagent II, the portfolio of $\mathrm{SCF}_{2} \mathrm{PO}(\mathrm{OEt})_{2^{-}}$ containing compounds was significantly extended, opening further the chemical space of $\mathrm{SCF}_{2} \mathrm{FG}$-containing molecules and offering new possibilities for potential applications.

\section{Acknowledgements}

This work was partially supported by INSA Rouen, Rouen University, CNRS, EFRD, Labex SynOrg (ANR-11-LABX-0029), Région Normandie (Crunch Network) and Innovation Chimie Carnot (I2C). F. P.-C., B.F., T. B. thanks the European Research Council (ERC) under the European Union's Horizon 2020 research and innovation program (grant agreement no. 758710). F. P.-C. thanks the Region Normandy for a doctoral fellowship.

Keywords: Fluorine; sulfur; diethyl phosphonodifluoromethylthiolation reagent, radical pathway; synthetic methodologies

[1] a) T. Liang, C. N. Neumann, T. Ritter, Angew. Chem. Int. Ed. 2013, 52, 8214-8264; b) T. Besset, T. Poisson, X. Pannecoucke, Chem. Eur. J. 2014, 20, 16830-16845; c) C. Ni, J. Hu, Chem. Soc. Rev. 2016, 45, 5441-5454; d) G. Landelle, A. Panossian, F. R. Leroux, Curr. Top. Med. Chem. 2014, 14, 941-951; e) G. Landelle, A. Panossian, S. Pazenok, J.-P. Vors, F. R. Leroux, Beilstein J. Org. Chem. 2013, 9, 24762536; f) P. A. Champagne, J. Desroches, J.-D. Hamel, M. Vandamme, J.-F. Paquin, Chem. Rev. 2015, 115, 9073-9174; g) E. Merino, C. Nevado, Chem. Soc. Rev. 2014, 43, 6598-6608; h) H. Egami, M. Sodeoka, Angew. Chem. Int. Ed. 2014, 53, 8294-8308; i) M.-C. Belhomme, T. Besset, T. Poisson, X. Pannecoucke, Chem. Eur. J. 2015, 21, 12836-12865; j) T. Besset, P. Jubault, X. Pannecoucke, T. Poisson, Org. Chem. Front. 2016, 3, 1004-1010; k) H.-X. Song, Q.-Y. Han, C.-L. Zhao, C.-P. Zhang, Green Chem. 2018, 20, $1662-1731$.

[2] a) J. Wang, M. Sánchez-Roselló, J. L. Aceňa, C. del Pozo, A. E. Sorochinsky, S. Fustero, V. A. Soloshonok, H. Liu, Chem. Rev. 2014, 114, 2432-2506; b) S. Purser, P. R. Moore, S. Swallow, V. Gouverneur, Chem. Soc. Rev. 2008, 37, 320-330; c) E. P. Gillis, K. J. Eastman, M. D. Hill, D. J. Donnelly, N. A. Meanwell, J. Med. Chem. 2015, 58, 8315-8359; d) E. A. Ilardi, E. Vitaku, J. T. Njardarson, J. Med. Chem. 2014, 57, 2832-2842; e) Fluorine in Life Sciences: Pharmaceuticals, Medicinal Diagnostics, and Agrochemicals, 1st ed., Progress in Fluorine Science Series, (Eds.: G. Haufe, F. R. Leroux), Elsevier, Academic Press, 2018.

[3] D. O'Hagan, Chem. Soc. Rev. 2008, 37, 308-319.

[4] a) H.-Y. Xiong, X. Pannecoucke, T. Besset, Chem. Eur. J. 2016, 22, 16734-16749; b) X. Pannecoucke, T. Besset, Org. Biomol. Chem. 2019, 17, 1683-1693 and references therein.

[5] J. Wang, H.-Y. Xiong, E. Petit, L. Bailly, X. Pannecoucke, T. Poisson, T. Besset, Chem. Commun. 2019, 55, 8784-8787.

[6] a) A. Konno, T. Fuchigami, J. Org. Chem. 1997, 62, 8579-8581; b) T. Lequeux, F. Lebouc, C. Lopin, H. Yang, G. Gouhier, S. R. Piettre, Org. Lett. 2001, 3, 185-188; c) A. Henry-dit-Quesnel, L. Toupet, J.-C. Pommelet, T. Lequeux, Org. Biomol. Chem. 2003, 1, 2486-2491; d) L. Aliouane, S. Chao, L. Brizuela, E. Pfund, O. Cuvillier, L. Jean, P.-Y. Renard, T. Lequeux, Bioorg. Med. Chem. 2014, 22, 4955-4960; e) C. De Schutter, E. Pfund, T. Lequeux, Tetrahedron 2013, 69, 5920-5926; f) M. V. Ivanova, A. Bayle, T. Besset, X. Pannecoucke, T. Poisson, Angew. Chem. Int. Ed. 2016, 55, 14141-14145; g) M. V. Ivanova, A. Bayle, X. Pannecoucke, T. Besset, T. Poisson, Eur. J. Org. Chem. 2017, 24752480; h) M. V. Ivanova, A. Bayle, T. Besset, X. Pannecoucke, T. Poisson, Chem. Eur. J. 2017, 23, 17318-17338; i) Y. Ou, L. J. Goossen, Asian J. Org. Chem. 2019, 8, 650-653.

[7] H.-Y. Xiong, A. Bayle, X. Pannecoucke, T. Besset, Angew. Chem. Int. Ed. 2016, 55, 13490-13494.

[8] For more details, see the supporting information.

[9] B. Xu, D. Li, L. Lu, D. Wang, Y. Hu, Q. Shen, Org. Chem. Front. 2018, 5, 2163-2166.

[10] Note that in absence of $\mathrm{LiBr}$, only traces of compound were detected.

[11] For related reactions for the introduction of the $\mathrm{SCF}_{2} \mathrm{H}$ and $\mathrm{SCH}_{2} \mathrm{~F}$ groups, see: a) D. Zhu, X. Shao, X. Hong, L. Lu, Q. Shen, Angew. Chem. Int. Ed. 2016, 55, 15807-15811; b) Q. Zhao, L. Lu, Q. Shen, Angew. Chem. Int. Ed. 2017, 56, 11575-11578; c) S.-H. Guo, X.-L. Zhang, G.-F. Pan, X.-Q. Zhu, Y.-R. Gao, Y.-Q. Wang Angew. Chem. Int. Ed. 2018, 57, 1663-1667. 